\title{
Socio-economic inequality and spatial heterogeneity in anaemia among children in India: Evidence from NFHS-4 (2015-16)
}

\author{
Himani Sharma $^{\mathrm{a}, *}$, S.K. Singh ${ }^{\mathrm{b}}$, Shobhit Srivastava ${ }^{\mathrm{a}}$ \\ ${ }^{a}$ International Institute for Population Studies, Mumbai, India \\ ${ }^{\mathrm{b}}$ Department of Mathematical Demography \& Statistics International Institute for Population Studies, Mumbai, India
}

\section{A R T I C L E I N F O}

\section{Keywords:}

Anaemia

Socio-economic inequality

Spatial

Burden

Autocorrelation

\begin{abstract}
A B S T R A C T
Objective: Prevalence of anaemia among children has been a major health problem in developing countries. An estimated 73 million children below age five in India (58\%) are anaemic (NFHS-4, 2017) despite of a number of vertical interventions across different states. This study has analysed the extent of socio-economic inequalities and spatial heterogeneity in anaemia among children using data from the recent round of Indian DHS, known as National Family Health Survey.

Methods: Bivariate and multivariate logistic regression analysis were used to assess the effects of socio-economic and demographic predictors on prevalence of anaemia among children under age five. Socio-economic inequalities in the prevalence of anaemia among children were analysed using Concentration Index and Poor-rich Ratios. Further, the spatial heterogeneity in the prevalence of anaemia were analysed using autocorrelation and auto regression models.

Results: The highest negative values of Concentration Index and Poor-rich ratios were observed in Mizoram $(-0.204)$ and Nagaland $(-0.120)$. The univariate Moran's I statistics was 0.63 for child anaemia suggesting a profound and significant spatial heterogeneity in the prevalence of anaemia among children in India. The spatial autocorrelation of anaemia among children with anaemia among mother was 0.46 . Other predictors included in the model having significant autocorrelation with anaemia among children were underweight (0.74) and experience of diarrhoea in seven days preceding the survey (0.35). The results of SEM explained that coefficients of mother's anaemia (0.74), uneducated mothers $(0.10)$ and underweight children $(0.10)$ were some of the key predictors of child anaemia in India.

Conclusion: The study findings suggest greater investment in addressing micronutrient deficiencies among children and child feeding practices, by adopting differential approaches especially in the regions with higher prevalence of anaemia.
\end{abstract}

\section{Introduction}

Anaemia among children is still persistent as a major public health problem in the developing countries. In the current scenario of 21st century, where developed nations are heading towards new innovations and achievements, the developing nations are still fighting with calamitous problems like poverty, hunger, and malnutrition. They are more vulnerable to anaemia as they are going through a phase of transition due to socio-economic changes as well as emergence of global market systems. Childhood anaemia is viewed as severe and calls for public health interventions irrespective of urban residence, better wealth status and educational achievements. ${ }^{1}$ The most recent rounds of $\mathrm{Na}$ tional Family Health Survey (2015-16 NFHS-4) estimated that 58\% of children age 6-59 months were anaemic (haemoglobin levels below $11.0 \mathrm{~g} / \mathrm{dl}$ ), an improvement over the NFHS-3 estimate of $69 \%{ }^{2}$ Anaemia is caused due to the reduction of red blood cells and haemoglobin level in the blood. It is the result of lack of nutritional intake of iron, folates, vitamin A, B12 and other micro-nutrients. Anaemia may turn out to be disastrous for children as it reduces their physical and mental ability and leads to retarded cognitive development. It also leads to children who eventually may have less mental strength and weak physical, social and emotional development along with multiple morbidities. Poor nutrition and diseases have been seen as the main factors responsible for health deterioration in infants at complementary stage. ${ }^{3}$ The steps taken to eradicate malnutrition and anaemia have not been accomplishing enough to overcome the pertaining situation. Both the

\footnotetext{
* Corresponding author. 13/97 Rani Mandi, Allahabad, 211003, India.

E-mail addresses: himani.sharma446@gmail.com, himanisharma@iips.net (H. Sharma), drsks@iips.net (S.K. Singh), shobhitsrivastava889@gmail.com (S. Srivastava).
} 


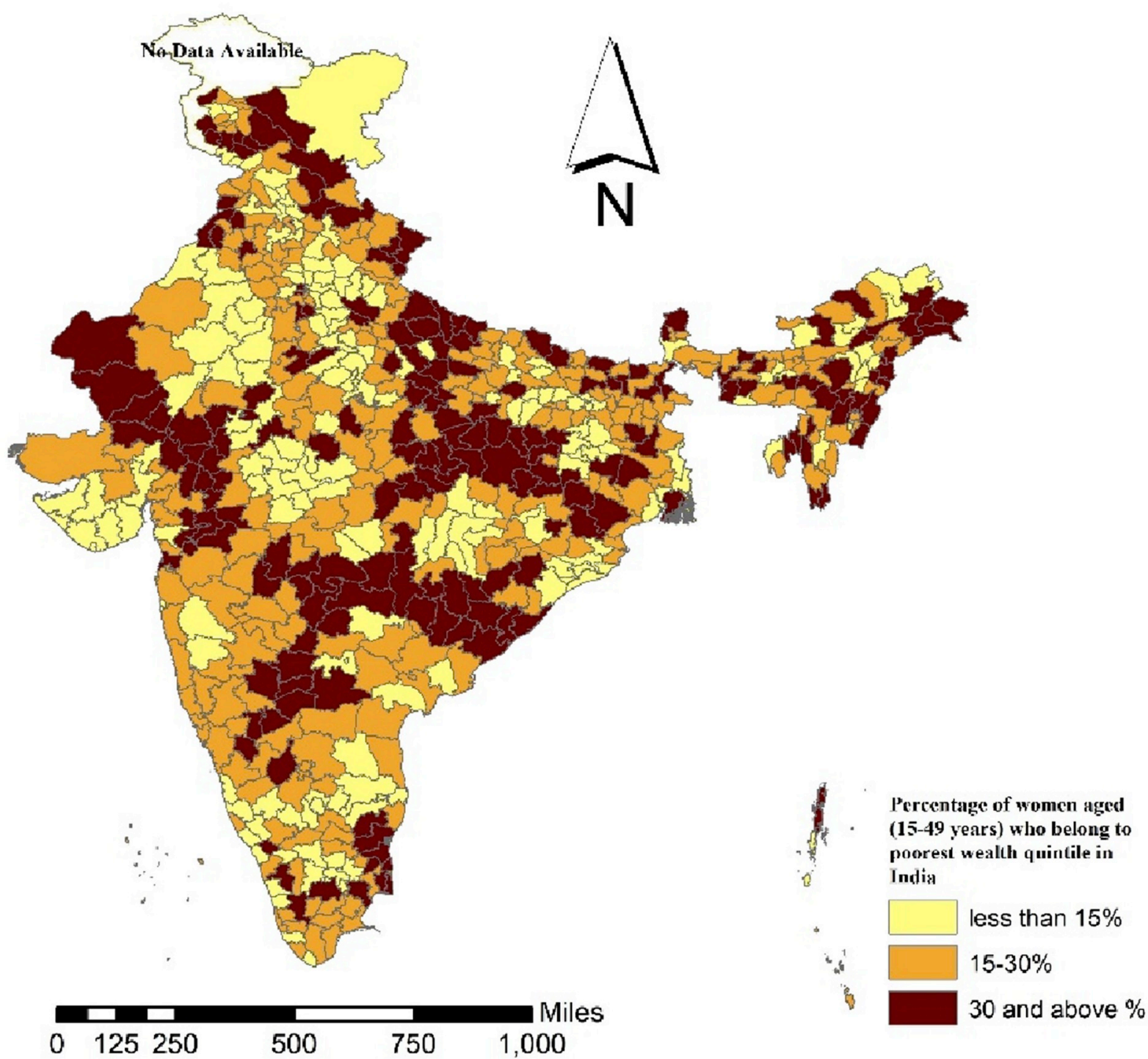

Fig. 1. Choropleth Map depicting distribution of Poorest Wealth Quantile for 640 disticts of India, NFHS, 2015-16.

Millennium Development Goals (MDGs) and Sustainable Development Goals (SDGs) and have identified the problem of malnutrition by setting many targets, and India is committed towards-halving the prevalence of underweight children by 2015- as a key indicator for achieving the MDG of eradicating extreme poverty and hunger (Fig. 1). ${ }^{4}$

Despite concerted efforts to address malnutrition among children globally, the Hunger Statistics are worsening overtime. Now 815 million people are going to bed hungry, up from 777 million in 2015. It is pretty evident from this year's Global nutrition report that how malnutrition and its related effects have grown over the years. A total of 125 countries are facing the burden of anaemia; 52 are facing a double burden of anaemia and overweight; whereas 38 countries are facing a double burden of stunting and anaemia (Fig. 2).

In a 2002 report, the World Health Organization listed iron deficiency, a major cause of anaemia, as one of the top 10 risk factors in developing countries for "lost years of healthy life". Anaemia is associated with premature births, intrauterine growth retardation, and low birthweight among infants. In turn, premature, underdeveloped, and underweight infants have decreased chances of survival. ${ }^{6}$ The prevalence of underweight children is amongst the highest in the world, and nearly double that of in less developed and developing countries. Nearly 60 million children are underweight in India. ${ }^{7}$ Referring to a study carried out in SriLanka, multiple and interrelated determinants are involved in the development of anaemia; therefore, an understanding of the complex and subtle causes of anaemia is important to develop appropriate interventions and target at-risk populations (Fig. 3). ${ }^{8}$

A cross sectional study conducted in Uttarakhand, India reflects that a significant proportion of the apparently healthy children suffer from overt anaemia and they have latent iron deficiency and the possible reason for this could be the rising trend of consuming snacks and junk foods in all the socio economic status. ${ }^{9}$ Cutting the pulsing umbilical cord before iron rich cord blood is transferred to the new-born also results in lower iron in the infant at birth. ${ }^{10} \mathrm{~A}$ study found that socio- 


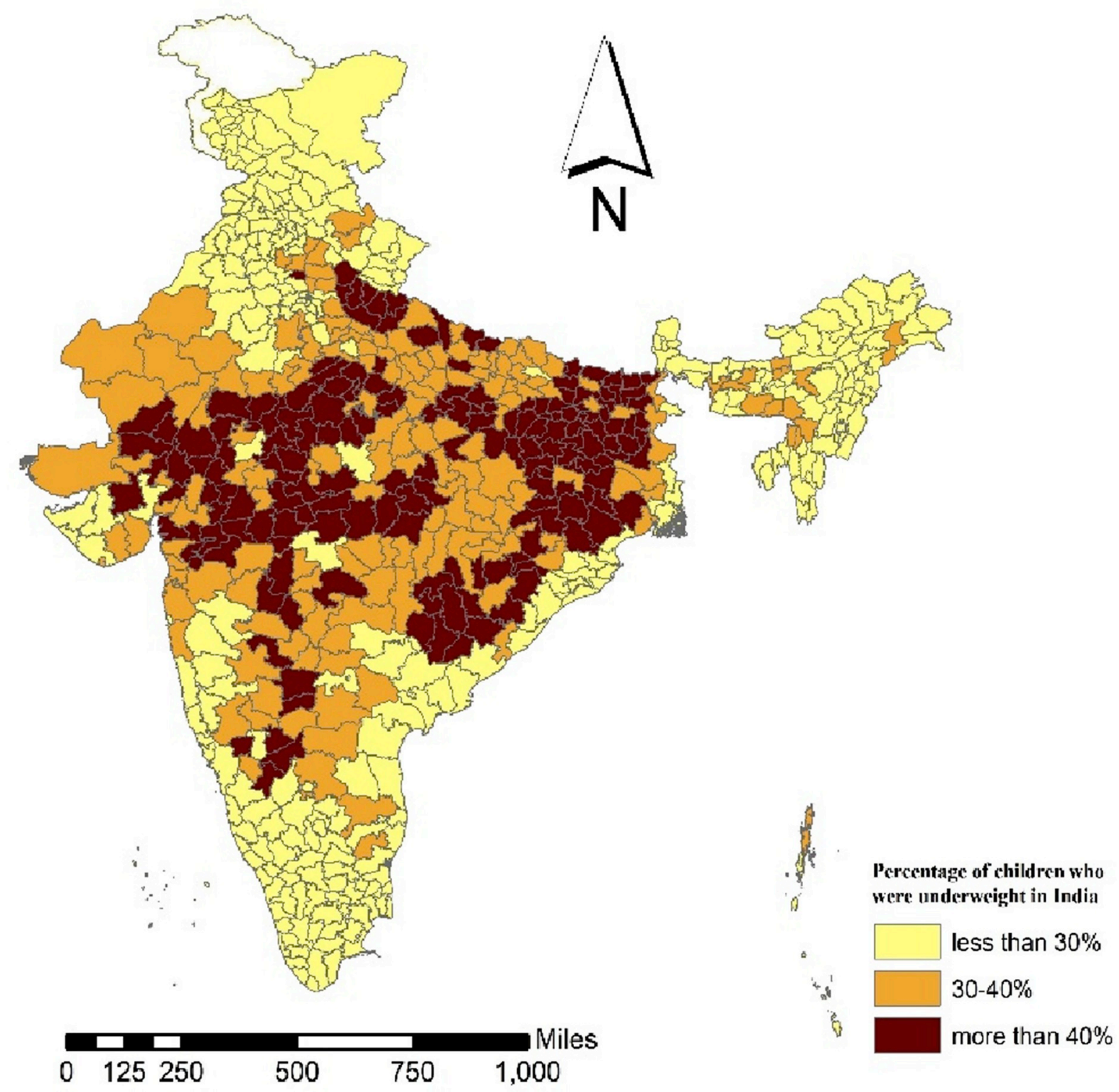

Fig. 2. Choropleth Map depicting distribution of Underweight Children for 640 disticts of India, NFHS, 2015-16.

economic gradient plays a major role in under-nutrition and works through the pathway of higher intra-household inequity in several child and mother specific factors (Figs. 4 and 5). ${ }^{11}$

A study based on socioeconomic inequality in India suggests that in India, the gap in prevalence of underweight children among the rich and the poor households is increasing over the years with wide regional differentials. ${ }^{12}$ Results of a cross-sectional study in China reflected anaemia is widespread and that anaemic status is correlated with the adverse cognitive and psychological outcomes among the students. ${ }^{13}$ The proportion of malnourished children is rising due to structural adjustment programs, rising poverty, deteriorating infrastructure etc.

The present study analyses the socio-economic inequality in anaemia among children, spatial heterogeneity and correlates of anaemia across districts of India. Spatial heterogeneity is a special case of observed or unobserved heterogeneity which refers to patchy distribution of processes or events across a broad area or landscape provided by the social structure. In other words, spatial heterogeneity (sometimes referred to as sub-regional variation) refers to the uneven distribution or pattern of a trait, event or any indicator across any region. There are enormous districts in India and are heterogeneous in terms of socio-economic and demographic indicators. A very scarce information is available about the spatial heterogeneity of anaemia cases in the districts of India. ${ }^{14}$ Being a large scale sample survey, NFHS-4 provides estimates for several important indicators of malnutrition among children, which provide a helping hand to understand the disparity and socio-economic inequality in anaemia. Most of the studies have been dedicated towards analysing the levels and trends of anaemia among children at national or state level. The districts of India are at par with each other and depict enormous heterogeneity. Very little information is available about the spatial heterogeneity of anaemia among children at district level. Therefore, a district level spatial analysis of anaemia is much needed considering the fact that nutrition varies from place to place and has a significant impact on the health of children in India.

\section{Data and methods}

The data used for the study is taken from the fourth round of 


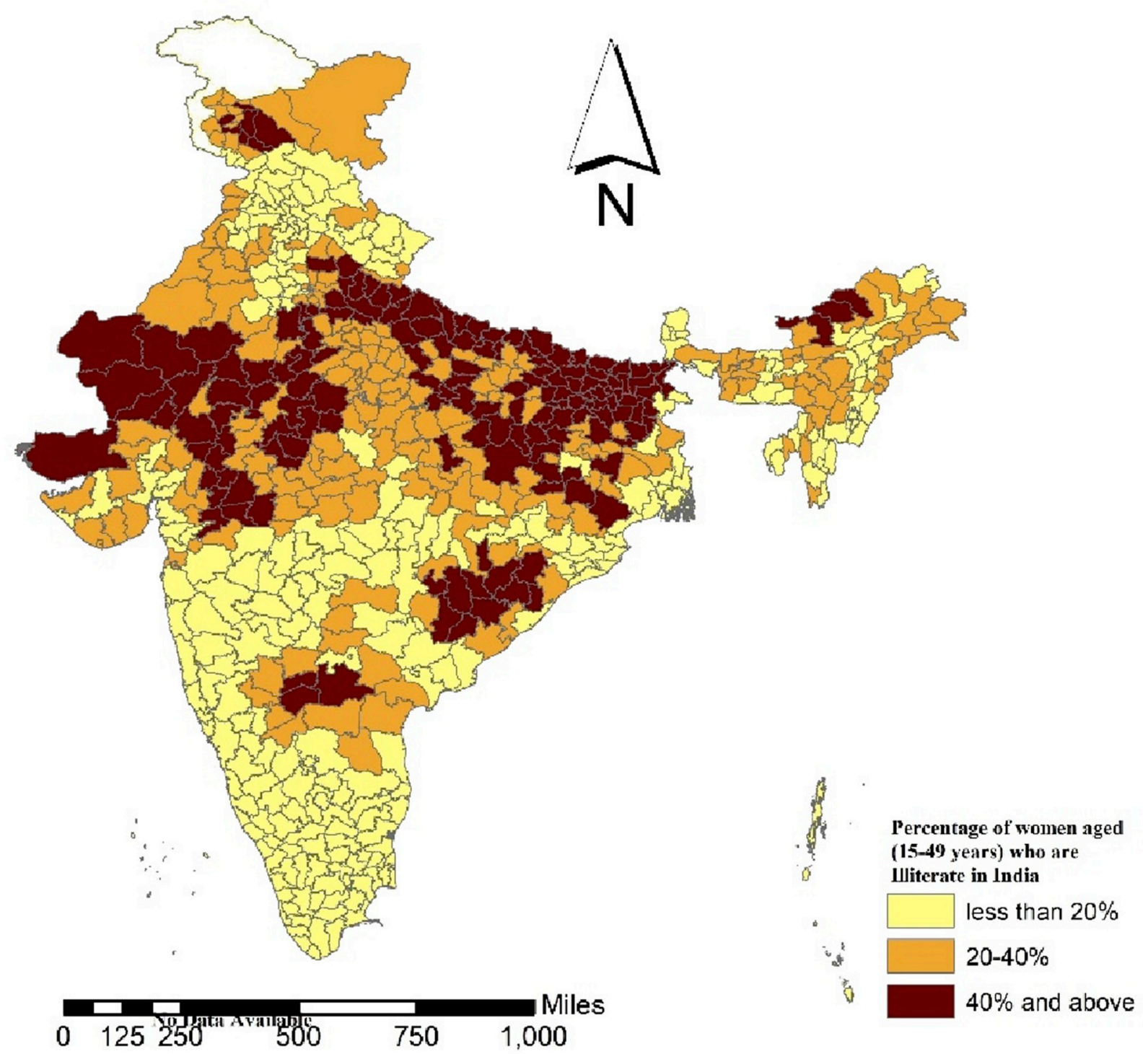

Fig. 3. Choropleth Map depicting distribution of Illiterate women for 640 disticts of India, NFHS, 2015-16.

National Family Health Survey (2015-2016) conducted by the International Institute for Population Sciences, Mumbai. NFHS provides comprehensive information on several aspects of child nutrition for states as well as districts of India. NFHS-4 covered a nationally representative sample of 601,509 households, 699,686 women aged 15-49 years and 103,525 men aged 15-54 years in India. In NFHS, 2015-16 haemoglobin testing was performed on all children age 6-59 months in the sample households using capillary blood. The testing of haemoglobin was done through a portable battery operated device called HemoCue $\mathrm{Hb} 201+$ analyser. The final sample size of eligible children for anaemia testing included in the analysis was 221,858 . The testing of anaemia was completed successfully for $91 \%$ of eligible children. The consent was taken from a parent or any guardian responsible for the child. As per the standards of NFHS, children were considered anaemic when their haemoglobin level was below $11.0 \mathrm{~g} /$ dL; mildly anaemic (10.0-10.9), moderately anaemic (7.0-9.9), severely anaemic (less than 7.0). Haemoglobin levels were adjusted for altitude in enumeration areas that are above $1,000 \mathrm{~m}$. The children who were identified to have severe anaemia were referred to nearby health care centre for further treatment and evaluation.

\subsection{Outcome variable}

Prevalence of anaemia among children is used as the dependent variable in the study. The dependent variable is dichotomous having 0 as "Not Anaemic" and 1 as "Anaemic". For the bivariate analysis, three levels of anaemia were also considered, i.e., mild, moderate and severe.

\subsection{Independent variables}

A set of background characteristics of the households along with factors associated with child and mother were used based on prior literature and availability of data. Residence, religion, caste, wealth quantile, regions were taken as key background characteristics having implications for the variation in the prevalence of anaemia among children. Factors related to children included age of the child, sex of the child, experience of Diarrhoea (in last 2 weeks), experience of Fever (in last 2 weeks), birth order, nutritional status, and vitamin A supplementation. Similarly, age of mother, education of mother, mother's anaemia status, mother's nutritional status/BMI (Body Mass Index), parity of mother, number of ANC (Antenatal Care) visits while pregnant with the index child and place of delivery were used as maternal factors in the study. 


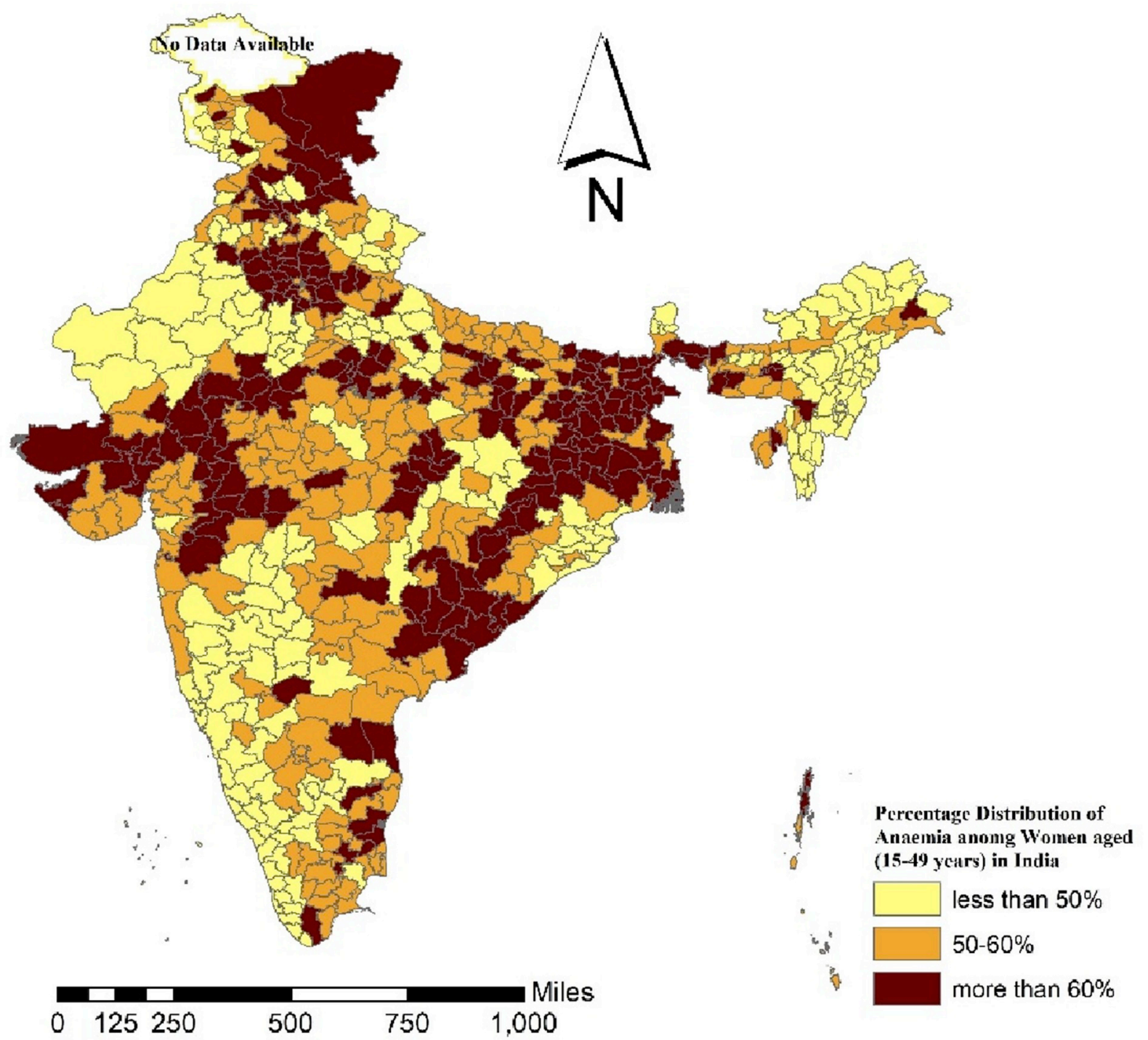

Fig. 4. Choropleth Map depicting distribution of Anemia among Mothers for 640 disticts of India, NFHS, 2015-16.

\section{Methods}

The paper has used bivariate analysis to analyse the prevalence of anaemia among children by various background characteristics. Binary Logistic regression analysis was used to assess the effects of socio-economic characteristics on the dichotomous dependent variables of the study. The logistic regression constituted three different models, i.e., Model 1 included only background characteristics and children's characteristics factors; Model 2 included background and maternal factors while Model 3 was the full effect model controlling background as well as children and maternal factors. Socio-economic inequality exits in the prevalence of anaemia among children based on several socio-economic factors. For this, a widely used standard tool that examines the magnitude of socio-economic inequality in any health outcome, i.e. Concentration Index (CI) is employed to study the extent of inequity in anaemia across all 36 States/UTs of India. ${ }^{15}$ The value of concentration index ranges from -1 to +1 . When the outcome value is 0 , it implies no socio-economic inequality. In NFHS, households are given scores based on the number and kinds of consumer goods they own using Principal Component Analysis. Wealth quintiles are compiled by assigning the household score to each household member, ranking each person in the household population by their score, and then dividing the distribution into five equal categories, each with $20 \%$ of the population. ${ }^{2}$ In the analysis, we have only considered the poorest and richest wealth quantiles for calculating the poor-rich ratios. As the wealth quantile is arranged from the lowest to highest quantile, a negative value indicates the concentration of relevant health variable, e.g. anaemia in the lowest wealth quantiles and vice versa for the positive value of +1 . The poor-rich ratios are being calculated for the states of India, which is defined as the ratio of the poorest to the richest wealth quintile, which has been used to measure the gap in child malnutrition. ${ }^{12}$

Further, to analyse the spatial clustering in the prevalence of anaemia among children below age five, Univariate and Bivariate Moran's I statistic along with a set of regression models have been employed. Moran's I is the measure of spatial autocorrelation. It is a generalization of Pearson's correlation coefficient. ${ }^{16}$ Spatial autocorrelation indicates the degree to which data points are similar or dissimilar to their spatial neighbours. The formula to compute the Moran's I statistic is as follows ${ }^{17}$ :

Moran's I $=\frac{n}{S_{O}} \times \frac{\sum_{i} \Sigma_{j} W_{i j}\left(x_{i}-\bar{X}\right)\left(Y_{j}-\bar{Y}\right)}{\sum_{i}\left(y_{i}-\bar{Y}\right)^{2}}$

where $\mathrm{x}$ and $\mathrm{y}$ are the variables of interest; $\bar{X}$ is the mean of $\mathrm{x} ; \bar{Y}$ is the mean of $\mathrm{y} ; \mathrm{n}$ is number of spatial units; $W_{i j}$ is the standardized weight matrix between observation $\mathrm{i}$ and $\mathrm{j}$ with zeroes on the diagonal; and $S_{O}$ 


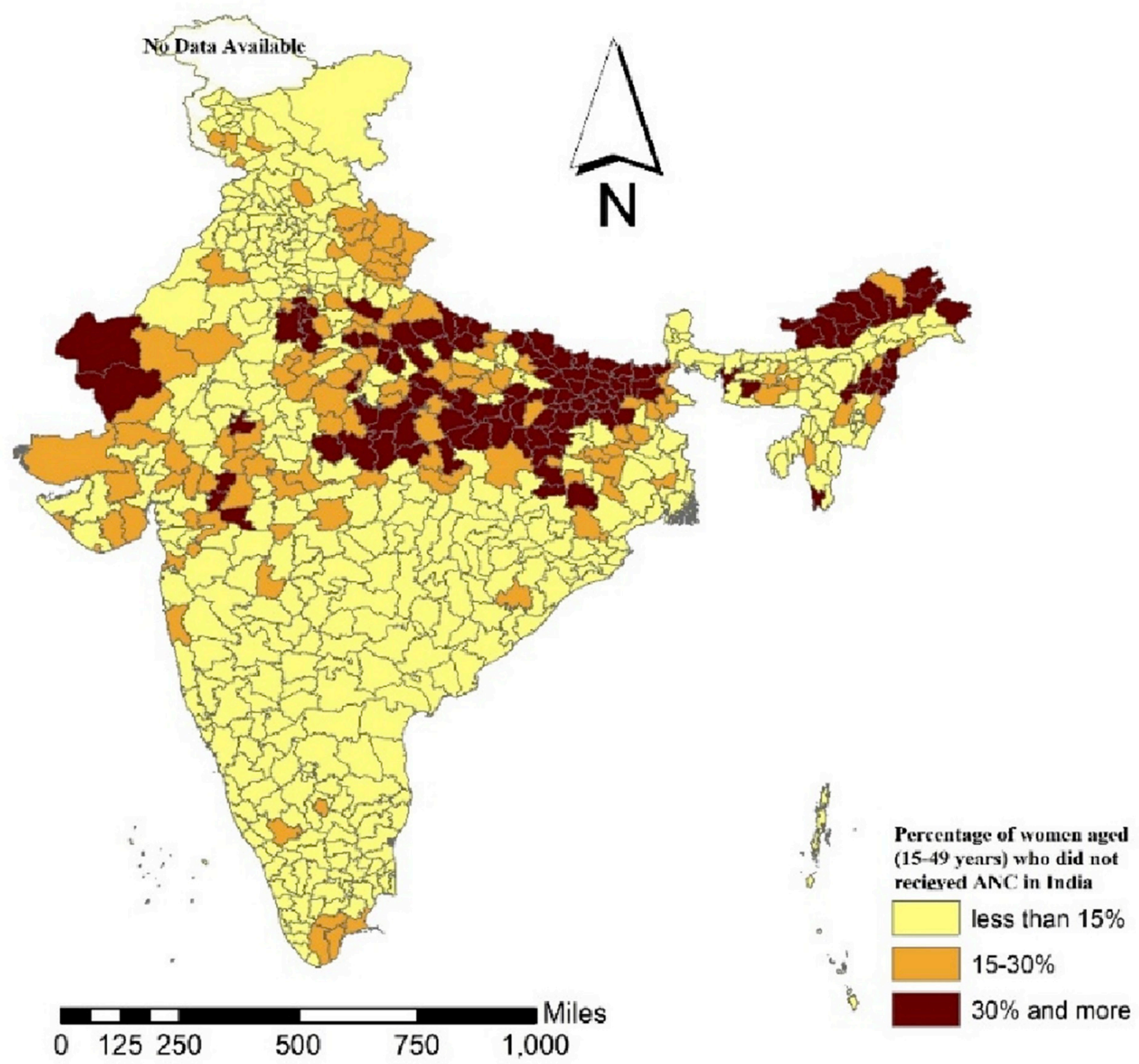

Fig. 5. Choropleth Map depicting distribution of No ANC visits for 640 disticts of India, NFHS, 2015-16.

is the aggregate of all spatial weights, i.e. $S_{O}=\Sigma_{i} \Sigma_{j} W_{i j}$. The spatial weights $\mathrm{W}_{\mathrm{ij}}$ are non-zero when $\mathrm{i}$ and $\mathrm{j}$ are neighbours, else it remains zero. The weight used in the analysis is Queen Contiguity Weights, which simply indicate whether spatial units share a boundary or not. If the set of boundary points of unit I is denoted by bnd (i), then the Queen Contiguity Weight is defined by:

$W_{i j}=\left\{\begin{array}{cc}1, & \text { bnd }(i) \cap \text { bnd }(j) \neq \varnothing \\ 0, & \text { bnd }(i) \cap \text { bnd }(j) \neq \varnothing\end{array}\right.$

However, this allows the possibility that spatial units share only a single boundary point (such as a shared corner point on a grid of spatial units). Hence a stronger condition is to require that some positive portion of their boundary be shared.

Value of Moran's- I ranges from -1 (indicating perfect dispersion) to +1 (perfect correlation). A zero value indicates a random spatial pattern. Negative (positive) values indicate a negative (positive) spatial autocorrelation. Positive autocorrelation indicates that points with similar attribute values are closely distributed in space, whereas negative spatial autocorrelation indicates that closely associated points are more dissimilar. For comparison purposes, the Cluster maps made from Geary's C, also a measure of spatial autocorrelation have been provided in the appendix section as well.
Univariate Moran's I measure the correlation of neighbourhood values around a specific spatial location. It determines the extent of spatial non-stationery and clustering present in the data. Bivariate Moran's I examines the local correlation between a variable and weighted average of another variable in the neighbourhood. In other words, it examines the relationship between the exposure and the outcome variables for the geographic region of India. ${ }^{14}$ While both univariate and bivariate Moran's I aim to measure similarities and dissimilarities of spatial data, they are found to be less useful in case of uneven spatial clustering. Hence, the univariate Moran's statistics depicts the extent of spatial autocorrelation of any indicator. It confirms the clustering of districts in terms any socioeconomic or demographic and health predictors whereas the Bivariate Moran's I statistics depicts spatial autocorrelation for the dependent variable against the correlates. $^{17}$

Spatial clusters have been identified through Univariate and Bivariate LISA (Local Indicators of Spatial Analysis) maps. In order to analyse the significant correlates of anaemia among children, a set of regression models have been used. Spatial OLS (Ordinary Least Square) regression was used to see the extent of autocorrelation in the error term. Since the OLS confirmed spatial autocorrelation in its error term for all three outcome variables, we further estimated spatial lag model 
(SLM) and Spatial Error Model (SEM). The underlying assumption of a spatial lag model is that the observations of the dependent variable are affected in the neighbourhood areas whereas the spatial error model is used to consider the effect of those variables which are not present in the regression model but have an effect on the outcome variable. The basic difference between the two models is that the spatial lag model unlike spatial error model does not consider the spatial dependence in the error term. ${ }^{18}$ After analysing the AIC (Akaike Information Criterion) value, we found that the spatial error is the best fit model for the study.

Spatial lag model suggests that the units are spatially dependent to each other and lagging to each in the nearby spatial locations. A typical spatial lag model can be written as follows:

$Y_{i}=\delta \sum_{j \neq 1} W_{i j} Y_{j}+\beta X_{j}+\varepsilon_{j}$

here $Y_{i}$ denotes the prevalence of anaemia among children for the $i^{\text {th }}$ district, $\delta$ is the spatial autoregressive coefficient, $W_{i j}$ denotes the spatial weight of proximity between district $\mathrm{i}$ and $\mathrm{j}, Y_{j}$ is the prevalence of anaemia in the $j^{\text {th }}$ district, $\beta_{j}$ denotes the coefficient, $X_{j}$ is the predictor variable and $\varepsilon j$ is the residual.

Spatial error model on the other hand, considers the contribution of omitted variables which are not included in the model but can have significant effect in the analysis. A Spatial Error Model (SEM) is expressed as follows:

$Y_{i}=\beta X_{j}+\lambda \sum_{j \neq 1} W_{i j} Y_{j} \varepsilon_{j}+\varepsilon_{i}$

here, $Y_{i}$ denotes the prevalence of anaemia for the $i^{\text {th }}$ district, $\lambda$ is the spatial autoregressive coefficient, $W_{i j}$ denotes the spatial weight of proximity between district $\mathrm{i}$ and $\mathrm{j}, Y_{j}$ is the prevalence of anaemia in the $j^{\text {th }}$ district, $\beta_{j}$ denotes the coefficient, $X_{j}$ is the predictor variable and $\varepsilon_{i}$ is the residual. ${ }^{19}$

ArcGIS version 10.4, GeoDa version 1.12, STATA 13.1 and MS office package are used for analysing the data throughout the study.

\section{Results}

Findings of this study portray a significant inequality in the prevalence of anaemia among children in India by some selected socioeconomic and maternal factors (Table 1). The highest prevalence rates of moderate anaemia have been observed among children of age 12-23 months $(40.5 \%)$, children from Scheduled castes $(30.7 \%)$ and scheduled tribes (33.4\%), children from households with most despairing wealth index (33.1\%) and children from Central (33.8\%) and Northern $(32.7 \%)$ regions. A rural-urban differential is virtually existent as the children from rural areas were found having a higher proportion of moderate $(29.9 \%)$ and mild anaemia $(28.2 \%)$ than their urban counterparts. The lowest prevalence of children with anaemia was observed in the Christian religion (19.1\%) in comparison to their counterparts. Male children were presenting a higher prevalence of severe (1.6\%) and moderate anaemia $(29.6 \%)$, whereas mild anaemia was more prevalent among females $(28.4 \%)$. Both moderate $(29.6 \%)$ and mild anaemia (28.6\%) were prevalent among children born to young mothers (age less than 20 years). A significantly higher percentage of moderate anaemia (35.4\%) was observed among children whose mother did not go for ANC. A higher prevalence of mild and moderate anaemia was found among children who were delivered at home [(28.6\%), (31.5\%)]. Similarly, children who had diarrhoea (35.9\%) and fever in the last two weeks $(33.2 \%)$ had a higher prevalence of moderate anaemia. A higher percentage of underweight children were moderately (33.0\%) and mildly $(28.4 \%)$ anaemic. A significantly higher proportion of children suffered from moderate (34.1\%) and mild anaemia (28.8\%) when their mothers were anaemic.

Table 2 presents results of multiple logistic regression models, portraying adjusted effects of various socio-economic factors on prevalence of anaemia among children in India. Model 1 consists of the
Table 1

Percentage of Children with different levels of Anaemia by some selected background Characteristics, NFHS 2015-16.

\begin{tabular}{|c|c|c|c|}
\hline Background characteristics & Severe & Moderate & Mild \\
\hline \multicolumn{4}{|l|}{ Age of the child } \\
\hline 6-11 months & 1.78 & 37.56 & 29.24 \\
\hline 12-23 months & 2.63 & 40.45 & 27.51 \\
\hline 24-35 months & 1.77 & 31.94 & 28.67 \\
\hline 36 and above & 0.88 & 20.42 & 27.27 \\
\hline \multicolumn{4}{|l|}{ Type of Residence } \\
\hline Urban & 1.67 & 27.59 & 26.86 \\
\hline Rural & 1.52 & 29.9 & 28.22 \\
\hline \multicolumn{4}{|l|}{ Religion } \\
\hline Hindu & 1.57 & 29.43 & 27.84 \\
\hline Muslim & 1.64 & 29.75 & 27.85 \\
\hline Christian & 0.93 & 19.08 & 25.79 \\
\hline Others & 1.19 & 28.51 & 29.14 \\
\hline \multicolumn{4}{|l|}{ Caste } \\
\hline Scheduled caste & 1.67 & 30.73 & 28.35 \\
\hline Scheduled tribe & 1.47 & 33.36 & 28.95 \\
\hline Obc & 1.61 & 29.42 & 27.63 \\
\hline others & 1.49 & 26.25 & 27.21 \\
\hline \multicolumn{4}{|l|}{ Wealth Quantile } \\
\hline Poorest & 1.67 & 33.13 & 28.35 \\
\hline Poorer & 1.69 & 30.73 & 28.92 \\
\hline Middle & 1.53 & 29.49 & 27.95 \\
\hline Richer & 1.47 & 27.15 & 27.34 \\
\hline Richest & 1.37 & 23.74 & 26.01 \\
\hline \multicolumn{4}{|l|}{ Regions } \\
\hline North & 2.27 & 32.67 & 26.37 \\
\hline Central & 2.13 & 33.8 & 26.96 \\
\hline East & 1.04 & 28.53 & 29.93 \\
\hline North East & 0.43 & 12.35 & 24.09 \\
\hline West & 1.32 & 26.4 & 29.02 \\
\hline South & 1.3 & 26.05 & 27.09 \\
\hline
\end{tabular}

Maternal characteristics

Age at Maternity

Less than 20

20-24

$25-29$

30-34

35 and above

Mother's Educational level

No Education

Primary

Secondary

1.93

1.64

1.39
1.09

Mother Anaemic

No

Yes

Mother's nutritional status

Below 18.5 (U-weight)

18.5-24.99(normal)

25- $30+$ (overweight)

1.09

1.91

7.09

1

2 and 3

4 and above

ANC visits

No ANC

1 to 3

4 and above

Place of delivery

Home delivery

Institutional delivery

29.61

$29.61-28.60$

$29.81 \quad 27.69$

$26.49 \quad 26.61$

$25.48 \quad 24.66$

$26.56 \quad 25.71$

$34.32 \quad 28.77$

$30.75 \quad 28.26$

$26.85 \quad 27.55$

$22.75 \quad 25.76$

$22.93 \quad 26.59$

$\begin{array}{ll}34.07 & 28.79\end{array}$

$32.5 \quad 28.38$

$29.12 \quad 28.1$

$24.38 \quad 25.91$

$28.46-27.91$

$28.47 \quad 27.89$

$\begin{array}{ll}32.79 & 27.58\end{array}$

$35.4 \quad 27.8$

$32.75 \quad 28.16$

$27.97 \quad 27.63$

Child characteristics

Sex of the Child

Male

Female

Diarrhoea in last 2 weeks No

Yes

29.58

31.46

28.67
1.5

Nutritional status
28.59

35.9

26.67 
Table 1 (continued)

\begin{tabular}{llll}
\hline Background characteristics & Severe & Moderate & Mild \\
\hline Normal & 1.28 & 27.2 & 27.53 \\
Underweight & 2.08 & 32.99 & 28.41 \\
Birth order & & & \\
1 & 1.33 & 26.5 & 27.77 \\
2 & 1.54 & 29.02 & 27.84 \\
3 & 1.68 & 31.75 & 28.37 \\
4 and above & 2.08 & 34.43 & 27.45 \\
Nutrition (vitamin A) & & & \\
No & 1.68 & 29.66 & 27.88 \\
Yes & 1.48 & 28.95 & 27.81 \\
Fever & & & \\
No & 1.47 & 28.66 & 28.08 \\
Yes & 2.18 & 33.19 & 26.23 \\
\hline
\end{tabular}

background factors along with specific factors related to children. It is evident from the results of Model 1 that rural children were more likely to be anaemic than their urban counterparts [OR $=0.97, \mathrm{p}<0.05$, $95 \% \mathrm{CI}=0.94,0.99]$. With reference to religion and caste, children who belonged to Muslim religion [OR $=1.15, \mathrm{p}<0.05,95 \%$ $\mathrm{CI}=1.12,1.18]$ and ST category $[\mathrm{OR}=1.23, \mathrm{p}<0.05,95 \%$ $\mathrm{CI}=1.19,1.27]$ were more likely to be anaemic than their respective counterparts. The likelihood of anaemia was lower among children from richest wealth quintiles $[\mathrm{OR}=0.72, \mathrm{p}<0.05,95 \% \mathrm{CI}=0.7$, $0.75]$ as compared to those from the poorest households. Children residing in north-eastern region were less likely $[O R=0.34, p<0.05$, $95 \% \mathrm{CI}=0.33,0.36]$ to be anaemic than those from the northern region. A higher likelihood of anaemia among children was found in the age group 12-23 months [OR $=1.15, \mathrm{p}<0.05,95 \% \mathrm{CI}=1.11,1.2]$ than their respective counterparts. Children having diarrhoea in the two weeks preceding the survey were significantly more likely to be anaemic $[\mathrm{OR}=1.04, \mathrm{p}<0.05,95 \% \mathrm{CI}=1.01,1.08$ ]. Similarly, underweight children had higher likelihood of being anaemic $[\mathrm{OR}=1.36, \mathrm{p}<0.05,95 \% \mathrm{CI}=1.33,1.39]$. Results portray that birth order of the children was positively and strongly associated with anaemia among children. Children of birth order 4 or above were more likely to be anaemic [OR $=1.14, \mathrm{p}<0.05,95 \% \mathrm{CI}=1.11,1.18]$ compared to those having birth order one. In model II, which includes background and maternal factors, age at maternity is negatively associated with anaemia among children. Similarly, educational attainment showed a negative association with anaemia, where children of educated mothers had the least likelihood of having anaemia $[\mathrm{OR}=0.67$, $\mathrm{p}<0.05,95 \% \mathrm{CI}=0.63,0.7]$. On the other hand, children with anaemic mothers showed a higher likelihood of having anaemia $[\mathrm{OR}=1.84, \mathrm{p}<0.05,95 \% \mathrm{CI}=1.8,1.88]$. It was found that children belonging to normal $[\mathrm{OR}=0.91, \mathrm{p}<0.05,95 \% \mathrm{CI}=0.89,0.94]$ and overweight mother [OR $=0.86, \mathrm{p}<0.05,95 \% \mathrm{CI}=0.83,0.89$ ] showed lower likelihood of having anaemia than the underweight ones. ANC visit was negatively associated with anaemia as the children showed lower likelihood of having anaemia when the mothers had $4+$ ANC visits [OR $=0.89, \mathrm{p}<0.05,95 \% \mathrm{CI}=0.86,0.92]$. Surprisingly, children born with institutional care showed higher likelihood of having anaemia than those delivered at home. $[\mathrm{OR}=1.03, \mathrm{p}<0.05$, $95 \% \mathrm{CI}=1,1.07]$. Model III is the full effect model consisting of all the factors included in the analysis. In model III, the factors showed similar association as model I \& II except the diarrhoea which lost its importance in the final model.

Table 3 shows the values of Concentration Index for children with anaemia in India with a spectrum of urban-rural place of residence. The negative values of concentration index portray concentration of anaemia among children from poor households. Seven important and diverse states of India, i.e., Mizoram, Nagaland, Telangana, Odisha, Andhra Pradesh, country capital Delhi, and West Bengal depict the highest negative value reflecting a heavy burden of anaemia among poor children. It confirms the fact that children from the poorer section of the society share a higher burden of anaemia across these states of India. The negative values of $\mathrm{CI}$ in urban areas also reflect an alarming situation; the highest negative value is observed in Assam, followed by Chhattisgarh, Nagaland, Mizoram, Odisha, Tripura, Delhi, Andhra Pradesh and Kerala. For the rural mate, the highest negative values are found in Mizoram followed by Nagaland, Odisha, West Bengal, Andhra Pradesh and Delhi. In these states, prevalence of anaemia is more pronounced among children from rural poor households. The calculated poor-rich ratios for each state represent a situation of poor being marginalised in terms of health and nutrition in comparison to rich. The highest value for poor rich ratios are found in many of the north-eastern states like Nagaland, Mizoram, Manipur, Tripura etc. The lowest value of poor-rich ratio in the prevalence of anaemia was found in Sikkim implying that the anaemia is equally shared by both sections of the society.

The spatial analysis presents the spatial pattern in anaemia among children across different districts of India. Fig. 6 is a quantile map depicting anaemia among children through three broad categories; low (7.87-37.18), medium (37.18-66.49) and high (66.49-95.80). It is evident from Fig. 6 that 213 among 640 districts were classified as low in the prevalence of anaemia among children, 214 as medium and 213 as high. A substantial number districts with high anaemia among children were from the states of Gujarat, Uttar Pradesh, Bihar etc.

Table 4.1 depicts the Univariate and Bivariate Moran's I statistics for anaemia among children in India across 640 districts of India. The univariate Moran's I value for anaemia among children is 0.63 (statistically significant) which shows that anaemia among children is spatially clustered across Indian districts. Amongst all the factors, the Moran's I value was the highest for underweight children followed by uneducated mothers, scheduled caste, mother being anaemic and underweight women. With regard to Bivariate Moran's I value, it was found that spatial autocorrelation was highest with anaemia and underweight children (0.74), followed by anaemic mother (0.46), diarrhoea (0.35) and child's age (0.14). Similarly, factors like caste and mother's education depicted a negative autocorrelation with anaemia. Fig. 7 shows Bivariate LISA (Local Indicators of Spatial Association) maps that depict the spatial association between independent variables and dependent variable. Fig. 7 presents the Bivariate LISA map (Map (a) \& (b)) which indicated that 72 of 640 districts (about 11\%) higher proportion of anaemic children and higher proportion of children age 6-11 months while a cluster of 90 districts (about 14\%) were found as of high anaemia and high mother anaemia. In case of Map (a), the districts identified were mostly belonging to the states of Gujarat, Uttar Pradesh, Madhya Pradesh, Bihar, Haryana and some parts of Jammu and Kashmir and Himachal Pradesh while the hotspots for Map (b) were Jammu and Kashmir, Gujarat, Himachal Pradesh, Jharkhand, Madhya Pradesh, Uttar Pradesh, Andhra Pradesh and some parts of Bihar (Fig. 7).

In Fig. 7 (Map c, d \& e), a total of 88 districts were identified as hotspots of high anaemia and high underweight children as per map (c) while 77 districts were identified as cold spots. The hotspots belonged mainly to Gujarat, Madhya Pradesh, Rajasthan, Uttar Pradesh, Uttarakhand, Bihar, Jharkhand, Andhra Pradesh and Karnataka.

Similarly, major clusters of high anaemia and high underweight mothers were found in 77 of 640 districts majorly belonging to the states of Uttar Pradesh, Bihar, Jharkhand, Rajasthan, Gujarat, Karnataka and Andhra Pradesh (map d). Map (e) suggested that around 60 districts constitute the hotspots (high anaemia and high diarrhoea among children) whereas 22 districts constitute the cold spots (low proportion of anaemic children and low prevalence of diarrhoea). The identified districts were mainly from the states of Jammu and Kashmir, Himachal Pradesh, Haryana, Rajasthan, Gujarat, Bihar, Jharkhand, Andhra Pradesh and Karnataka.

Table 4.2 presents the spatial determinants and influential factors affecting the level of anaemia among children in India. After establishing the significant Bivariate Spatial association between the 
Table 2

Odds ratio of Child Anaemia in India by some selected background, Maternal and Child characteristics, NFHS $2015-16$.

\begin{tabular}{|c|c|c|c|c|}
\hline Background characteristics & Any Anaemia & Model 1 & Model 2 & Model 3 \\
\hline \multicolumn{5}{|l|}{ Type of Residence } \\
\hline Urban $^{\oplus}$ & 56.12 & 1 & 1 & 1 \\
\hline Rural & 59.63 & $0.97 *(0.94,0.99)$ & $0.96 *(0.94,0.99)$ & $0.97 *(0.94,0.99)$ \\
\hline \multicolumn{5}{|l|}{ Religion } \\
\hline Hindu ${ }^{\circledast}$ & 60.76 & 1 & 1 & 1 \\
\hline Muslim & 63.78 & $1.15^{*}(1.12,1.18)$ & $1.14 *(1.1,1.18)$ & $1.13 *(1.09,1.17)$ \\
\hline Christian & 58.66 & $0.68 *(0.65,0.71)$ & $0.76 *(0.72,0.81)$ & $0.77 *(0.73,0.82)$ \\
\hline Others & 54.95 & $1.11 *(1.05,1.16)$ & $1.15 *(1.09,1.22)$ & $1.17 *(1.1,1.23)$ \\
\hline \multicolumn{5}{|l|}{ Caste } \\
\hline Scheduled caste ${ }^{\circledast}$ & 60.76 & 1 & 1 & 1 \\
\hline Scheduled tribe & 63.78 & $1.23 *(1.19,1.27)$ & $1.19 *(1.15,1.24)$ & $1.2 *(1.15,1.25)$ \\
\hline Obc & 58.66 & $0.94 *(0.92,0.97)$ & $0.94 *(0.91,0.97)$ & $0.94 *(0.91,0.97)$ \\
\hline Others & 54.95 & $0.85 *(0.82,0.87)$ & $0.88 *(0.85,0.91)$ & $0.89 *(0.86,0.93)$ \\
\hline \multicolumn{5}{|l|}{ Wealth Quantile } \\
\hline Poorest ${ }^{\oplus}$ & 63.16 & 1 & 1 & 1 \\
\hline Poorer & 61.34 & $0.94 *(0.91,0.97)$ & $0.97(0.94,1)$ & $0.97(0.94,1.01)$ \\
\hline Middle & 58.98 & $0.89 *(0.87,0.92)$ & $0.96 *(0.92,0.99)$ & $0.97(0.93,1)$ \\
\hline Richer & 55.96 & $0.84 *(0.81,0.87)$ & $0.92 *(0.88,0.96)$ & $0.94 *(0.9,0.97)$ \\
\hline Richest & 51.11 & $0.72 *(0.7,0.75)$ & $0.85 *(0.81,0.89)$ & $0.87 *(0.83,0.91)$ \\
\hline \multicolumn{5}{|l|}{ Regions } \\
\hline North ${ }^{\circledast}$ & 61.31 & 1 & 1 & 1 \\
\hline Central & 62.9 & $1.00(0.97,1.02)$ & $1.02(0.98,1.05)$ & $0.99(0.96,1.03)$ \\
\hline East & 59.49 & $0.92 *(0.89,0.95)$ & $0.84 *(0.81,0.87)$ & $0.82 *(0.79,0.85)$ \\
\hline North East & 36.87 & $0.34 *(0.33,0.36)$ & $0.38 *(0.36,0.4)$ & $0.39 *(0.37,0.41)$ \\
\hline West & 56.75 & $0.81 *(0.78,0.85)$ & $0.88 *(0.84,0.92)$ & $0.86 *(0.82,0.91)$ \\
\hline South & 54.45 & $0.74 *(0.72,0.77)$ & $0.81 *(0.77,0.84)$ & $0.81 *(0.77,0.84)$ \\
\hline \multicolumn{5}{|l|}{ Maternal characteristics } \\
\hline \multicolumn{5}{|l|}{ Age at Maternity } \\
\hline $15-19^{\circledR}$ & 65.01 & & 1 & 1 \\
\hline $20-24$ & 61.52 & & $0.99(0.97,1.02)$ & $0.99(0.97,1.02)$ \\
\hline $25-29$ & 57.85 & & $0.94 *(0.9,0.98)$ & $0.94 *(0.91,0.98)$ \\
\hline $30-34$ & 56.09 & & $0.92 *(0.86,0.99)$ & $0.92 *(0.86,0.99)$ \\
\hline 35 and above & 56.09 & & $0.86 *(0.74,1)$ & $0.86(0.74,1)$ \\
\hline \multicolumn{5}{|l|}{ Mother's Educational level } \\
\hline No Education ${ }^{\circledast}$ & 65.03 & & 1 & 1 \\
\hline Primary & 60.65 & & $0.87 *(0.84,0.9)$ & $0.87 *(0.84,0.91)$ \\
\hline Secondary & 55.79 & & $0.77 *(0.74,0.79)$ & $0.78 *(0.75,0.8)$ \\
\hline Higher & 49.6 & & $0.67 *(0.63,0.7)$ & $0.68 *(0.65,0.72)$ \\
\hline \multicolumn{5}{|l|}{ Mother Anaemic } \\
\hline $\mathrm{No}^{\circledast}$ & 50.62 & & 1 & 1 \\
\hline Yes & 64.77 & & $1.84 *(1.8,1.88)$ & $1.83 *(1.79,1.87)$ \\
\hline \multicolumn{5}{|l|}{ Mother's nutritional status } \\
\hline below 18.5 (U-weight) $\circledast$ & 62.7 & & 1 & 1 \\
\hline $18.5-24.99$ (normal) & 58.67 & & $0.91 *(0.89,0.94)$ & $0.94 *(0.91,0.96)$ \\
\hline $25-30+$ (overweight) & 51.85 & & $0.86 *(0.83,0.89)$ & $0.9 *(0.86,0.93)$ \\
\hline \multicolumn{5}{|l|}{ Parity } \\
\hline $1^{\oplus}$ & 57.77 & & 1 & 1 \\
\hline 2 and 3 & 57.86 & & $1.03 *(1,1.06)$ & $1.07 *(1.04,1.1)$ \\
\hline 4 and above & 62.33 & & $1.02(0.98,1.05)$ & $1.11 *(1.06,1.16)$ \\
\hline \multicolumn{5}{|l|}{ ANC visits } \\
\hline No ANC ${ }^{\circledast}$ & 65 & & 1 & 1 \\
\hline 1 to 3 & 62.69 & & $0.95 *(0.92,0.98)$ & $0.95 *(0.92,0.99)$ \\
\hline 4 and above & 57.05 & & $0.89 *(0.86,0.92)$ & $0.91 *(0.87,0.94)$ \\
\hline \multicolumn{5}{|l|}{ Place OF delivery } \\
\hline Home delivery ${ }^{\circledast}$ & 61.69 & & 1 & 1 \\
\hline Institutional delivery & 57.85 & & $1.03 *(1,1.07)$ & $1.04 *(1.01,1.08)$ \\
\hline
\end{tabular}

Child characteristics

Age of the child
$6-11$ months ${ }^{\circledR}$
$12-23$ months
$24-35$ months
36 and above
Sex of the child
Male
Female
Diarrhoea in last 2 weeks
No
Yes
Nutritional Status
Normal

$\begin{array}{ll}68.58 & 1 \\ 70.58 & 1.15 *(1.11,1.2) \\ 62.37 & 0.75 *(0.72,0.78) \\ 48.57 & 0.43 *(0.41,0.44) \\ 58.49 & 1 \\ 58.83 & 1.01(0.99,1.03) \\ 58.02 & 1 \\ 64.98 & 1.04 *(1.01,1.08) \\ 56 & 1\end{array}$

1

$1.12 *(1.08,1.16)$

$0.72 *(0.69,0.75)$

$0.43 *(0.41,0.44)$

$-$

$-$

$-$

- $1.03(0.99,1.07)$

Normal $^{\circledR}$ 
Table 2 (continued)

\begin{tabular}{|c|c|c|c|c|}
\hline Background characteristics & Any Anaemia & Model 1 & Model 2 & Model 3 \\
\hline Underweight & 63.48 & $1.36 *(1.33,1.39)$ & - & $1.29 *(1.25,1.32)$ \\
\hline \multicolumn{5}{|l|}{ Birth order } \\
\hline $1^{\oplus}$ & 55.6 & 1 & - & - \\
\hline 2 & 58.4 & $1.05 *(1.03,1.07)$ & - & - \\
\hline 3 & 61.8 & $1.12 *(1.09,1.15)$ & - & - \\
\hline 4 and above & 63.96 & $1.14 *(1.11,1.18)$ & - & - \\
\hline \multicolumn{5}{|l|}{ Nutrition (vitamin A) } \\
\hline $\mathrm{No}^{\oplus}$ & 59.22 & 1 & - & 1 \\
\hline Yes & 58.24 & $0.99(0.98,1.01)$ & - & $1(0.98,1.02)$ \\
\hline \multicolumn{5}{|l|}{ Fever(in last 2 weeks) } \\
\hline $\mathrm{No}^{\circledast}$ & 58.21 & 1 & - & 1 \\
\hline Yes & 61.6 & $1.01(0.98,1.04)$ & - & $1.03(0.99,1.0)$ \\
\hline
\end{tabular}

${ }^{\circledR}$ Reference category; $\mathrm{P}<0.05^{*}$

dependent and independent variables, an Ordinary Least Square model (OLS) was fitted. The OLS model suggested that the residuals in the model were spatially auto correlated (Anaemia: Moran's $\mathrm{I}=0.63, \mathrm{p}$ value $=0.001$ ). Afterwards, Spatial Lag and Error Models were fitted on the data. Among the two estimated spatial models, Spatial Error Model provided the lowest AIC (Akaike Information Criteria) value and hence it was considered to be the appropriate model for the study. Spatial Error Model confirmed that the factors like anaemic mother, age of the child, uneducated mothers, underweight mother and children remained statistically significant predictors of anaemia among children.

The SEM model provided the final spatial estimates of correlates of anaemia among children across India (see Table 4.2). The value of Lambda was 0.683 which is highly significant and depicts that there is positive spatial autocorrelation among the regions having a high prevalence of anaemia among children in India. The coefficient of Anaemic mother was found to be the highest $(\beta=0.74)$ followed by underweight mothers $(\beta=0.19)$, uneducated mothers $(\beta=0.10)$ and underweight children $(\beta=0.10)$. The coefficient estimate for anaemic mothers confirmed that a 10-point increase in the proportion of women with anaemia was associated with 7.4-point increase in anaemia among children. Similarly, a 10-point increase in underweight mothers was associated with 1.9-point increase in anaemia among children. In the similar manner, a 10-point increase in uneducated mothers and underweight children were associated with a 1.0-point increase in anaemia among children.

\section{Discussion}

Among children of 6-59 months, anaemia is still considered to be a major public health problem in India. Though the levels of anaemia among children vary by background factors like rural residence and lowest household wealth quantile and maternal factors, more than half of the children in India are suffering either from mild or moderate anaemia. Quite significant proportion of children had mild and

Table 3

Poor-Rich ratio and Concentration Index depicting socio-economic inequality in Child Anaemia across Indian states, NFHS $2015-16$.

\begin{tabular}{|c|c|c|c|c|c|c|c|c|c|}
\hline \multirow[t]{2}{*}{ State } & \multicolumn{3}{|l|}{ Total } & \multicolumn{3}{|l|}{ Rural } & \multicolumn{3}{|l|}{ Urban } \\
\hline & C.I. & S.E. & $\mathrm{P} / \mathrm{R}$ & C.I. & S.E. & $\mathrm{P} / \mathrm{R}$ & C.I. & S.E. & $\mathrm{P} / \mathrm{R}$ \\
\hline Andhra Pradesh & $-0.071^{* * *}$ & 0.010 & 1.68 & $-0.055^{* * *}$ & 0.012 & 2.03 & $-0.079 * * *$ & 0.023 & 2.01 \\
\hline Arunachal Pradesh & $-0.055^{* * *}$ & 0.009 & 1.33 & $-0.054 * * *$ & 0.009 & 1.36 & $-0.040^{*}$ & 0.023 & 0.96 \\
\hline Assam & $-0.052^{* * *}$ & 0.009 & 1.28 & $-0.037^{* * *}$ & 0.009 & 1.06 & $-0.116^{* * *}$ & 0.035 & 1.77 \\
\hline Bihar & $-0.038^{* * *}$ & 0.003 & 1.38 & $-0.032^{* * *}$ & 0.003 & 1.40 & $-0.074^{* * *}$ & 0.010 & 1.43 \\
\hline Chhattisgarh & $-0.045^{* * *}$ & 0.008 & 1.36 & $-0.048^{* * *}$ & 0.009 & 1.35 & $-0.101^{* * *}$ & 0.016 & 1.53 \\
\hline Goa & -0.020 & 0.032 & 1.36 & 0.025 & 0.053 & 0.00 & -0.041 & 0.041 & 1.31 \\
\hline Gujarat & $-0.026^{* * *}$ & 0.006 & 1.09 & 0.005 & 0.007 & 1.09 & $-0.046^{* * *}$ & 0.011 & 1.29 \\
\hline Haryana & $-0.036^{* * *}$ & 0.004 & 1.26 & $-0.037 * * *$ & 0.005 & 1.28 & $-0.029 * * *$ & 0.009 & 1.17 \\
\hline Himachal Pradesh & -0.005 & 0.011 & 1.41 & -0.009 & 0.012 & 1.39 & 0.016 & 0.045 & 1.82 \\
\hline Jammu and Kashmir & $-0.053^{* * *}$ & 0.006 & 1.26 & $-0.046^{* * *}$ & 0.007 & 1.24 & $-0.065^{* * *}$ & 0.018 & 1.17 \\
\hline Jharkhand & $-0.044^{* * *}$ & 0.004 & 1.38 & $-0.030^{* * *}$ & 0.004 & 1.19 & $-0.090^{* * *}$ & 0.010 & 1.41 \\
\hline Karnataka & $-0.054 * * *$ & 0.006 & 1.26 & $-0.032^{* * *}$ & 0.007 & 1.31 & $-0.063^{* * *}$ & 0.011 & 1.33 \\
\hline Kerala & $-0.046^{* * *}$ & 0.017 & 1.52 & -0.025 & 0.022 & 1.50 & $-0.070^{* * *}$ & 0.028 & 0.00 \\
\hline Madhya Pradesh & $-0.027^{* * * *}$ & 0.003 & 1.16 & $-0.021^{* * *}$ & 0.003 & 1.15 & $-0.024 * * *$ & 0.006 & 1.19 \\
\hline Maharashtra & $-0.039 * * *$ & 0.006 & 1.30 & $-0.034 * * *$ & 0.007 & 1.24 & $-0.063^{* * *}$ & 0.011 & 1.31 \\
\hline Manipur & $-0.034^{* *}$ & 0.015 & 1.54 & $-0.040^{* *}$ & 0.018 & 1.61 & $-0.057^{* *}$ & 0.026 & 1.51 \\
\hline Meghalaya & $-0.036^{* * *}$ & 0.010 & 1.35 & $-0.028^{* * *}$ & 0.011 & 1.28 & -0.023 & 0.032 & 1.50 \\
\hline Mizoram & $-0.204 * * *$ & 0.018 & 1.98 & $-0.177^{* * *}$ & 0.020 & 1.91 & $-0.094 * * *$ & 0.034 & 1.57 \\
\hline Nagaland & $-0.120 * * *$ & 0.016 & 2.10 & $-0.120^{* * *}$ & 0.018 & 2.30 & $-0.100^{* * *}$ & 0.037 & 0.55 \\
\hline Delhi & $-0.074 * * *$ & 0.015 & 0.85 & $-0.073^{*}$ & 0.043 & 0.00 & $-0.073^{* * *}$ & 0.015 & 0.86 \\
\hline Odisha & $-0.101^{* * *}$ & 0.007 & 1.57 & $-0.097^{* * *}$ & 0.007 & 1.73 & $-0.099^{* * *}$ & 0.019 & 1.43 \\
\hline Punjab & $-0.040^{* * *}$ & 0.008 & 1.26 & $-0.019^{* *}$ & 0.009 & 0.94 & $-0.070^{* * *}$ & 0.013 & 1.47 \\
\hline Rajasthan & $-0.056^{* * *}$ & 0.004 & 1.23 & $-0.054^{* * *}$ & 0.004 & 1.30 & $-0.036^{* * *}$ & 0.009 & 1.35 \\
\hline Sikkim & 0.028 & 0.018 & 0.59 & 0.001 & 0.022 & 0.71 & $0.074 * *$ & 0.033 & 1.44 \\
\hline Tamil Nadu & $-0.042^{* * *}$ & 0.007 & 1.23 & $-0.022^{* * *}$ & 0.009 & 1.08 & $-0.052^{* * *}$ & 0.011 & 1.49 \\
\hline Tripura & $-0.033^{*}$ & 0.018 & 1.64 & -0.018 & 0.021 & 2.65 & $-0.093^{* *}$ & 0.039 & 0.67 \\
\hline Uttar Pradesh & $-0.007 * * *$ & 0.002 & 1.06 & $-0.008^{* * *}$ & 0.003 & 1.04 & $-0.044^{* * *}$ & 0.005 & 1.21 \\
\hline Uttarakhand & $-0.026^{* * *}$ & 0.007 & 1.08 & $-0.021^{* * *}$ & 0.008 & 1.08 & $-0.061^{* * *}$ & 0.013 & 1.30 \\
\hline West Bengal & $-0.068^{* * *}$ & 0.008 & 1.29 & $-0.076^{* * *}$ & 0.009 & 1.87 & $-0.078^{* * *}$ & 0.016 & 1.19 \\
\hline Telangana & $-0.091^{* * *}$ & 0.011 & 1.34 & $-0.047^{* * *}$ & 0.011 & 1.32 & $-0.057^{* *}$ & 0.023 & 1.48 \\
\hline
\end{tabular}

$\mathrm{P}<0.10 * \mathrm{P}<0.05 * * \mathrm{P}<0.01 * * *$ 


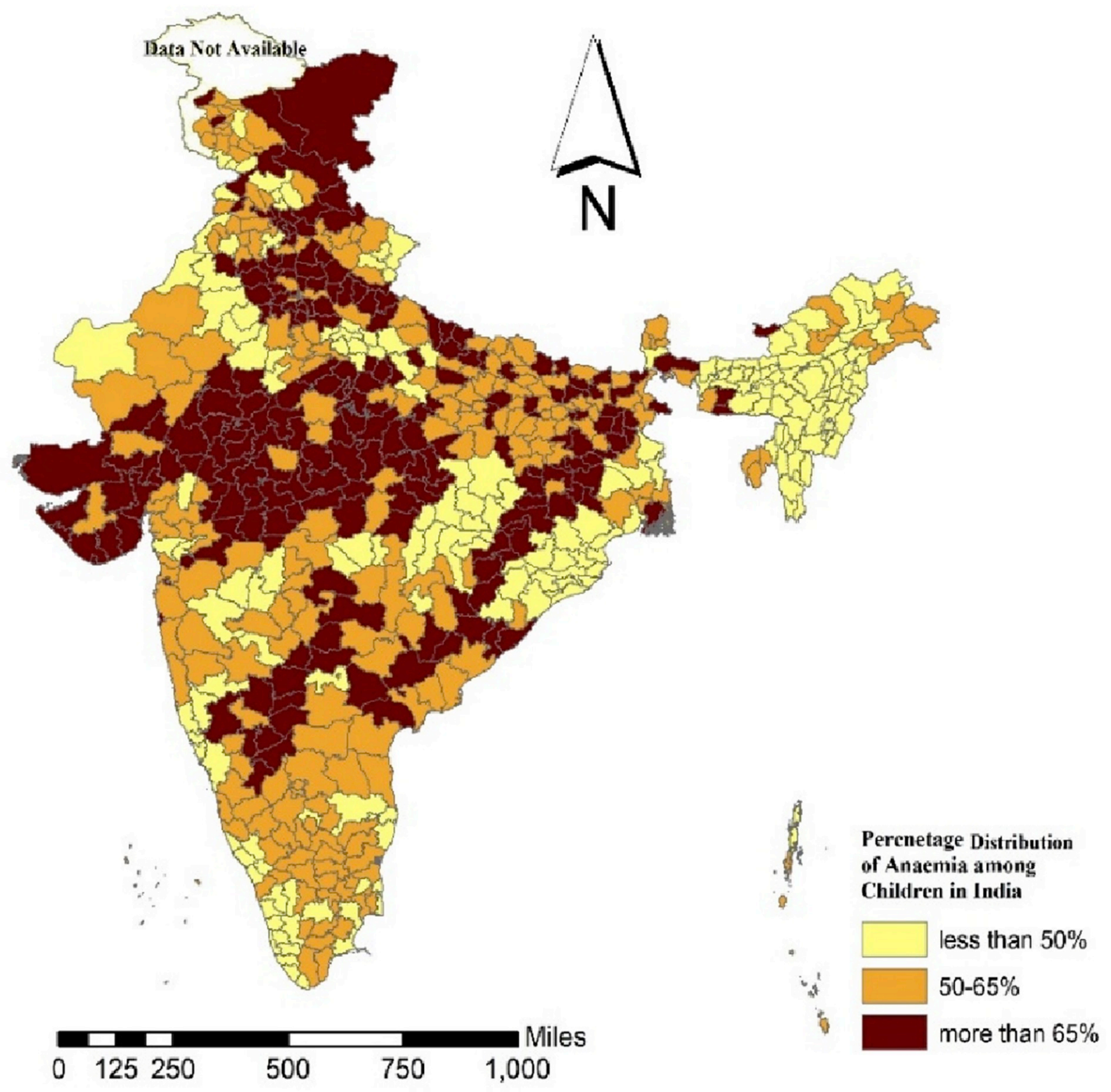

Fig. 6. Map of India showing geographical distribution of the rates of Anaemia among children aged 6-54 months across districts of India, NFHS-4.

Table 4.1

Moran's I statistics showing Spatial dependence of Child Anaemia and different independent variables across districts of Anaemia, NFHS 2015-16.

\begin{tabular}{lllll}
\hline & MORAN'S I & P value & Bi- MORAN'S I & P value \\
\hline \% Child Anaemic & 0.631 & 0.001 & - & - \\
\% Mother Anaemia & 0.564 & 0.001 & 0.469 & 0.001 \\
\% Child's age & 0.135 & 0.001 & 0.149 & 0.001 \\
\% Caste (ST) & 0.703 & 0.001 & -0.229 & 0.001 \\
\% Wealth quantile (poorest) & 0.352 & 0.001 & 0.035 & 0.023 \\
\% Mothers age (15-19) & 0.517 & 0.001 & - & - \\
\% Mothers education & 0.711 & 0.001 & -0.119 & 0.001 \\
$\quad$ (uneducated) & & & & \\
\% Underweight (women) & 0.676 & 0.001 & 0.275 & 0.001 \\
\% ANC visits (No ANC) & 0.634 & 0.001 & 0.070 & 0.001 \\
\% Home delivery & 0.664 & 0.001 & - & - \\
\% Underweight (child) & 0.743 & 0.001 & 0.743 & 0.001 \\
\% Diarrhoea & 0.354 & 0.001 & 0.354 & 0.001 \\
\% Fever & 0.313 & 0.001 & 0.313 & 0.014 \\
\% No vitamin A intake & 0.629 & 0.001 & 0.629 & 0.031 \\
\hline
\end{tabular}

moderate anaemia, while few remained in the severe category. An uneven patterning of anaemia is observed where the highest burden of anaemia is shared by the poorest people. Maternal age (35 years and above) shows a protective effect for anaemia in children. ${ }^{20}$ Similarly, mother's educational status is found to be negatively associated with the anaemia levels among children. Anaemia mother proved to be a significant biological factor of children suffering from anaemia. ${ }^{21} \mathrm{Re}-$ ligion wise, Christians were least likely to have any anaemia, in comparison to Hindus. ${ }^{22}$ Underweight mothers posed a threat to their children to acquire anaemia whereas children born to overweight mothers had shown the least likelihood. ANC visits of mothers had a significant impact on a child being anaemic. In our findings, deficiencies of vitamin A, children suffering from any disease such as diarrhoea or fever, low nutritional status of children were confirmed to be important risk factors of anaemia levels among children. These factors were found to be significantly associated with the prevalence of anaemia among children reported by other studies as well. ${ }^{23}$

The dissimilar values of concentration index reveal inequality in the prevalence of anaemia among children. It reflects that poor children suffer through a disproportionate burden of anaemia. Prior studies have 
also revealed this inherent socioeconomic inequality in anaemia among children in India. ${ }^{15}$ In terms of inequality among states, the highest variation is observed in the Northeastern states like Manipur, Nagaland and Tripura. Many studies have been conducted in the past in order to analyse the prevalent inequality concerning malnutrition and anaemia among children in North East. ${ }^{23}$ The findings of the study reveal a higher prevalence of worse anaemic status among children of the most indigent socioeconomic status. On the contrary, the children belonging to the highest and most well-off households are associated with better nutritional status and were less vulnerable to get anaemia. This proves the point here, that socioeconomic status becomes an important determinant of distribution of anaemia and malnutrition among children across the states. This socioeconomic inequality widens the gap between rich and poor and acts as an important factor of improving or degrading the development of an individual in the society and proves the fact that we are a deeply unequal society borne out by several yardsticks. ${ }^{23,24}$

From the spatial analysis, it was pretty clear that there is a positive autocorrelation between children with anaemia and their co-variates among the districts of India. Moran's I value is depicting high auto correlation meaning that anaemia among children has a spatial clustering across districts of India. The hotspots for child anaemia with its co-variates were found in the Western and Central regions of India. The states identified were Gujarat, Rajasthan, Madhya Pradesh, Haryana, Jammu and Kashmir and in some districts of Uttar Pradesh, Bihar, West Bengal, Odisha and Andhra Pradesh.

\section{Conclusion}

Anaemia is an interweaving outcome of several socioeconomic as well as behavioural factors associated with children. Although, India was one of its kind to launch the National Nutritional Anaemia Programme in 1970, anaemia remains predominant amongst children, women, adolescents and men. ${ }^{25}$ Several important issues emerged from the study, which may be useful in developing strategies under Anaemia Mukta Bharat programme which has been designed to reduce the prevalence of anaemia amongst young children (6-59 months), adolescents and women in the country. ${ }^{26}$ First, there is an effect of the standard of living and socioeconomic status on the likelihood of anaemia among children, as the children belonging to the lowest socioeconomic status depict the highest likelihood of anaemia in India. There is a wide disparity found regarding nutrition and care among children; hence, the advent of socioeconomic inequality seems to be never-ending. Second, the behavioural factors of the mother also tend to be important in determining the status of anaemia among children. Lastly, regional heterogeneity in anaemia among children across regions and districts are

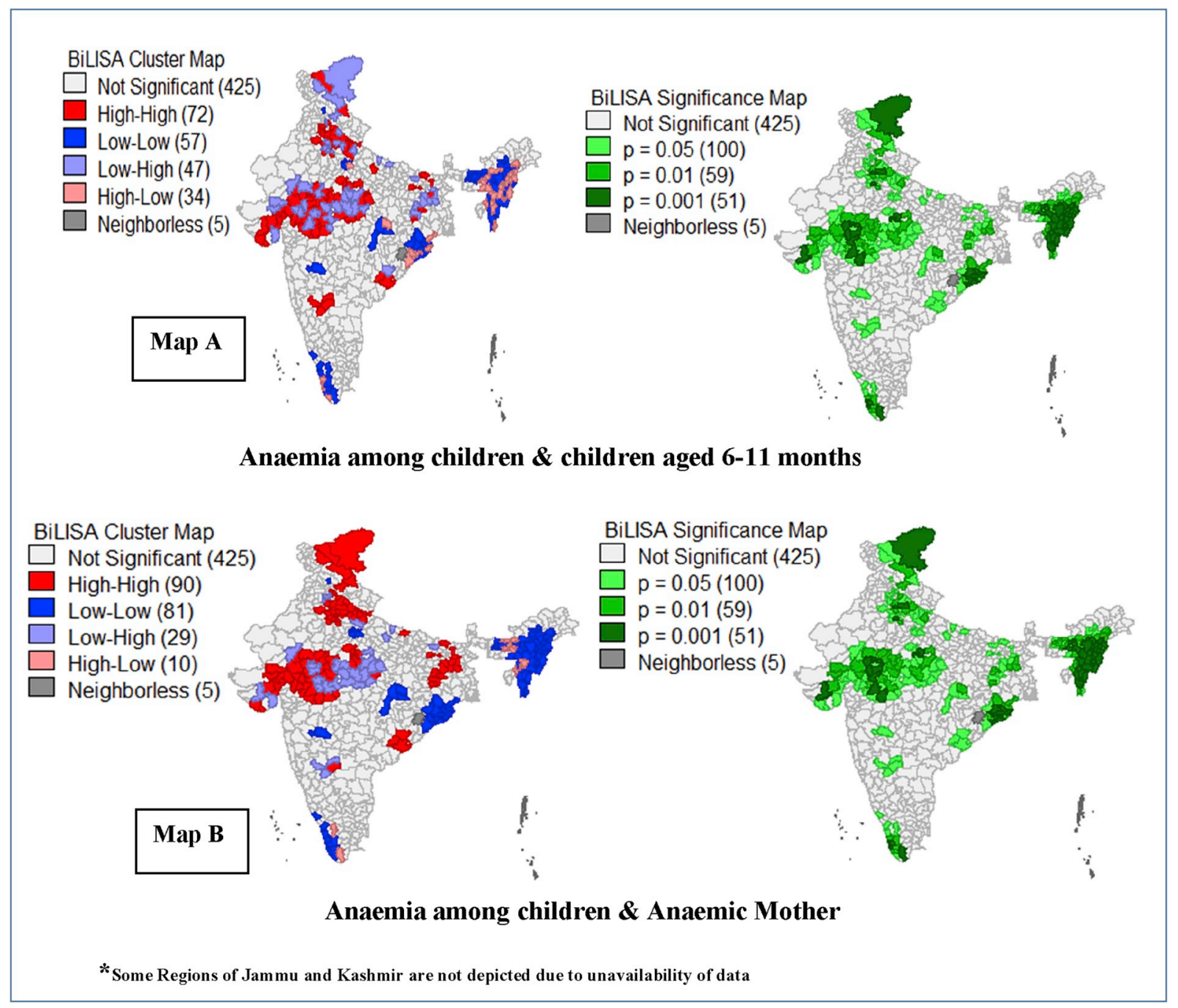

Fig. 7. Depicting Bivariate LISA Maps showing Spatial Correlation between Child Anaemia and its Co-variates. 


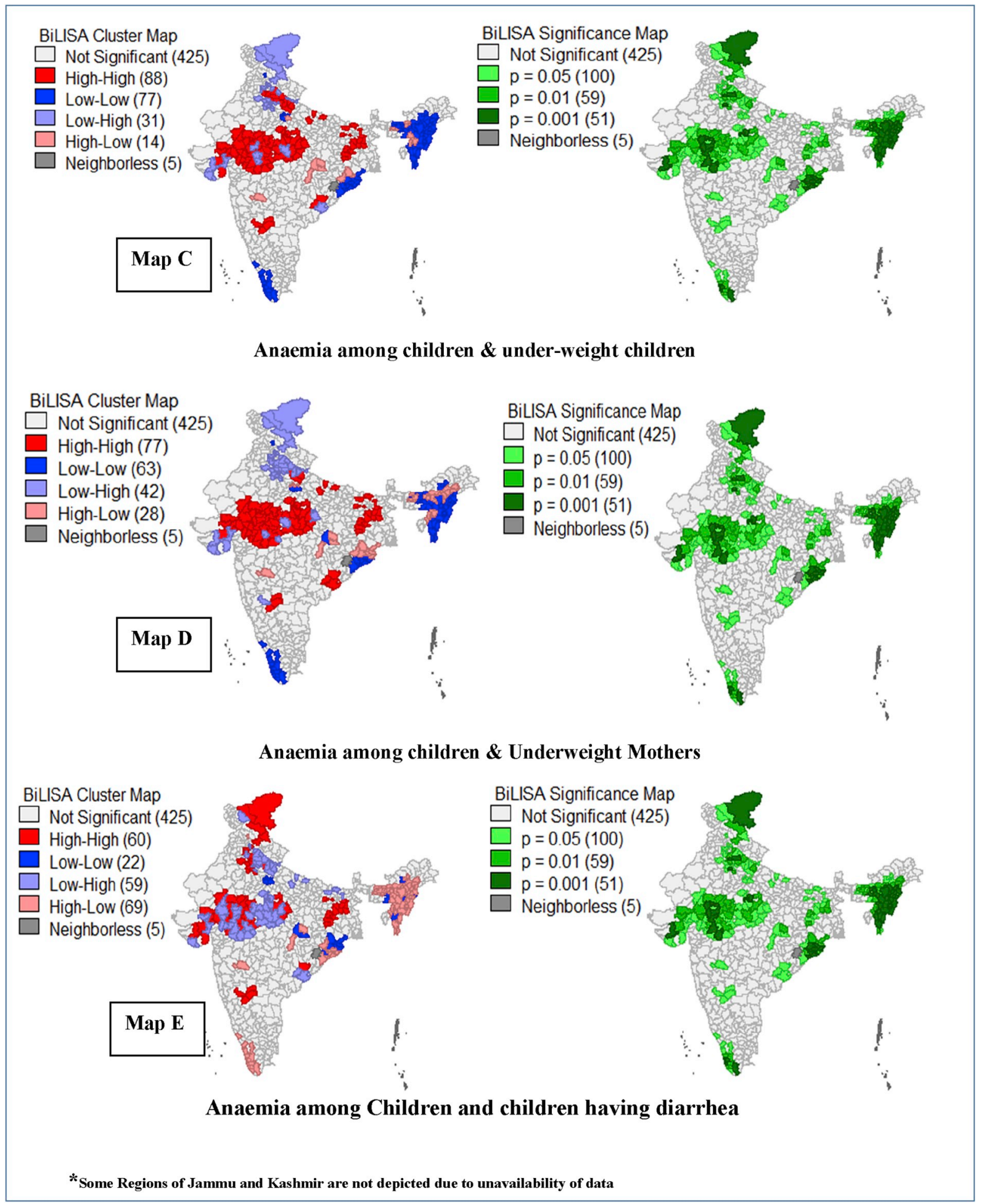

Fig. 7. (continued)

observed to in India. Bivariate LISA maps exemplify the clustering of the variables included in the study. These maps advocate the need to identify the districts/regions which need more attention and suggest more significant investment towards improving them.

The present study has some limitations as well. First, the cause and type of anaemia cannot be identified due to the nature of data. Second, the use of the HemoCue device which involves the test of capillary blood sample instead of venous blood in a laboratory might led to underestimation of anaemia to an extent. ${ }^{27}$
Considering the serious repercussions of anaemia on child's growth and development, it is essential to develop control and prevention strategies that address the issue of inequality in nutrition among children in Indian society. Since India is undergoing numerous socioeconomic and demographic transitions, it can be hypothesized that the nutritional status of the children in middle and high-income groups could be affected by the changes in dietary habits and lifestyle, leading to an increase in the prevalence of overweight, obesity and micronutrient deficiency. ${ }^{28}$ Keeping in mind the high prevalence of anaemia 
Table 4.2

OLS, Spatial Lag \& Spatial error model to assess the association between prevalence of Anaemia among children \& some selected socioeconomic factors in India, NFHS 2015-16.

\begin{tabular}{|c|c|c|c|c|c|c|}
\hline \multirow{2}{*}{ Indicators } & \multicolumn{2}{|l|}{ OLS Model } & \multicolumn{2}{|c|}{ Spatial Lag Model } & \multicolumn{2}{|c|}{ Spatial Error Model } \\
\hline & Coefficients & Sig. value & Coefficients & Sig. value & Coefficients & Sig. value \\
\hline$\%$ Mother Anaemic & 0.779 & 0.000 & 0.612 & 0.000 & 0.740 & 0.000 \\
\hline$\%$ Six-eleven age group child & 0.467 & 0.010 & 0.356 & 0.017 & 0.225 & 0.117 \\
\hline$\%$ ST population & -0.057 & 0.000 & -0.010 & 0.438 & 0.008 & 0.666 \\
\hline$\%$ Poorest quantile & -0.025 & 0.447 & -0.007 & 0.792 & -0.041 & 0.176 \\
\hline$\%$ Uneducated mothers & 0.164 & 0.000 & 0.076 & 0.005 & 0.107 & 0.003 \\
\hline$\%$ Underweight mothers & -0.339 & 0.000 & -0.262 & 0.000 & -0.161 & 0.008 \\
\hline$\%$ No ANC & -0.061 & 0.104 & -0.060 & 0.051 & -0.008 & 0.834 \\
\hline$\%$ Underweight child (5-59 m) & 0.277 & 0.000 & 0.154 & 0.005 & 0.104 & 0.101 \\
\hline \% Diarrhoea & -0.180 & 0.131 & -0.039 & 0.695 & -0.045 & 0.646 \\
\hline$\%$ Fever & 0.089 & 0.294 & 0.045 & 0.524 & 0.010 & 0.888 \\
\hline$\%$ Vit A (No) & -0.095 & 0.001 & -0.053 & 0.020 & -0.032 & 0.246 \\
\hline AIC VALUE & 4730.970 & & 4534.21 & & 4492.850 & \\
\hline LAMBDA & & & & & $0.683^{* * *}$ & 0.000 \\
\hline RHO & & & 0.467 & & & \\
\hline R-SQUARE & 0.356 & & 0.386 & & 0.418 & \\
\hline
\end{tabular}

in India and its association with several socio-economic, health and economic outcomes, sincere efforts are required to reduce this burden among children. ${ }^{29}$ Findings suggest that there is a dire need to formulate policies which aim at reducing anaemia among children, especially focusing on young children. Efforts should be made to reduce regional disparities, enhancing socio-economic status of the poor and needy children, providing equal opportunities of health and nutrition to all, improving education of women and reducing higher order births etc. to minimise the prevalence of anaemia among children in India.

\section{Declaration of competing interest}

The authors declare no Conflict of Interest.

\section{Appendix A. Supplementary data}

Supplementary data to this article can be found online at https:// doi.org/10.1016/j.cegh.2020.04.009.

\section{References}

1. Habte D, Asrat K, Magafu MGMD, et al. Maternal risk factors for childhood anaemia in Ethiopia published by : women's health and action research centre. Afr J Reprod Health. 2013;17(3):110-118.

2. Paswan Balram, Singh SK, Lhungdim Hemkhothang, et al. National family health survey (NFHS-4). 2017; 2017:199-249.

3. Practices F, Contributing F, Anaemia I, et al. To contributing anaemia wasting, stunting, and iron-deficiency among 3-23-month old children in kilosa district, rural Tanzania feeding practices and factors. J Health Popul Nutr. 2015;23(3):222-230.

4. United Nations. The Millennium Development Goals Report. United Nations; 2015:72.

5. Development Initiatives. Global Nutrition Report 2017: Nourishing the SDGs. 2017 2017:115.

6. Rae Galloway. Anemia prevention and control: what works: Part one: program guidance (English). Washington: DC: World Bank; 2003 1. In press.

7. Kanjilal B, Mazumdar PG, Mukherjee M, Rahman MH. Nutritional status of children in India : household socio-economic condition as the contextual determinant. 2010; 2010:1-13

8. Malkanthi RLDK, Silva KDRR, Jayasinghe-mudalige UK. Risk factors associated with high prevalence of anemia among children under 5 years of age in paddy-farming households in Sri Lanka. 2010;31(4):475-482
9. Jain N, Jain VM. Prevalence of anemia in school children. Med Pract Rev 2012;3(February):1-4.

10. Kraemer K, Zimmermann MB. Nutritional Anemia. Worldwide prevalence of anemia in preschool aged children, pregnant women and non-pregnant women of reproductive age. 2007; 2007:414

11. Mukherjee M. Childhood under-nutrition and SES gradient in India - myth or reality. Sci J Publ Health. 2015;3(1):119.

12. Pathak PK. Socioeconomic inequality in malnutrition in India, 1992-2005 socioeconomic inequality in malnutrition in India, 1992-2005. Popul (English. 2009(March) 1992-2005.

13. Counties P, Luo R, Zhang L, et al. Anaemia among students of rura Schools : prevalence and correlat qinghai's poor counties. 2019;29(5).

14. Anselin L. Thirty years of spatial econometrics. 2010;89(1).

15. Kanjilal B. Nutritional status of children in India : household socio- economic condition as the contextual determinant. Int J Equity Health. 2017;9(19):1-20.

16. Chen Y. New approaches for calculating Moran's index of spatial autocorrelation. PloS One. 2013;8(7)

17. Anselin L. Local indicators of spatial analysis-LISA. Geogr Anal. 1995;27(2):93-115

18. Khan J, Mohanty SK. Spatial heterogeneity and correlates of child malnutrition in districts of India. BMC Publ Health. 2018;18(1).

19. Khan J, Shil A, Prakash R. Exploring the spatial heterogeneity in different doses of vaccination coverage in India. 2018;13(11).

20. Leite MS, Cardoso AM, Coimbra Jr CE, et al. Prevalence of anemia and associated factors among indigenous children in Brazil: results from the First National Survey of Indigenous People's Health and Nutrition. Nutr J. 2013;12(69):1-11.

21. Habte D, Asrat K, Magafu MGMD, et al. Maternal risk factors for childhood anaemia in Ethiopia. 2019; 2019.

22. Balarajan YS, Fawzi WW, Subramanian SV. Changing patterns of social inequalities in anaemia among women in India: cross-sectional study using nationally representative data. BMJ Open. 2013;3(3)

23. Moatula Ao HL. Re-estimating malnourishment and inequality among children in north-east India. Econ Polit Wkly. 2014;6:53-63.

24. Lodha R, Jain Y, Sathyamala C. Reality of higher malnutrition. Among indian children. 2019;48(34):70-73.

25. Anand T, Medicine C, Rahi M, et al. Short title : issues in prevention of iron deficiency. 2014; 2014

26. Bhatia V, Sahoo DP, Parida SP. India steps ahead to curb anemia : anemia Mukt Bharat. 2018:30 04 .

27. Morales C, Levy TS, Me I, Tapia BM, Herna SV, Herna M. Validation of Masimo Pronto 7 and HemoCue 201 for hemoglobin determination in children from 1 to 5 years of age. 2017; 2017:1-9

28. Srihari G, Eilander A, Muthayya S, Kurpad a V, Seshadri S. Nutritional status of affluent Indian school children: what and how much do we know? Indian Pediatr. 2007;44(3):204-213.

29. Didzun O, De Neve J, Awasthi A, et al. Articles Anaemia among men in India : nationally representative cross-sectional study. Lancet Glob Health. 2019;7(12). 